\title{
A Quantitative Analysis of Creating Genius Loci in a Museum Based on Spatial Visibility Analysis
}

\author{
Jing Chen ${ }^{1}$, Yuwei Cao ${ }^{2,3,4}$ and JingJing Chen ${ }^{1}$ \\ ${ }^{1}$ Nanjing Audit University Jinshen College, Nanjing, 210023, China \\ ${ }^{2}$ Key Laboratory of Virtual Geographic Environment (Nanjing Normal University), Ministry of Education, Nanjing, 210023, China \\ ${ }^{3}$ State Key Laboratory Cultivation Base of Geographical Environment Evolution (Jiangsu Province), Nanjing, 210023, China \\ ${ }^{4}$ Jiangsu Center for Collaborative Innovation in Geographical Information Resource Development and Application, Nanjing, 210023, \\ China
}

\begin{abstract}
Analysing building styles and guiding architectural design with architectural phenomenology is essential for spatial design. Architectural phenomenology and especially shaping the genius loci facilitates emotional expression in design. This creates a building-human connection and a meaningful spatial social culture. It also provides a sense of direction and identity. However, architectural phenomenology is abstract and perceptual, helping designers create architecture through qualitative analysis. This complicates practical guidance during their creative process: it lacks a quantitative explanation of its practical design applications. This research focuses on the genius loci (a sense of direction and identity) in architectural phenomenology. It also explores how quantitative analysis creates a museum's genius loci. Associating architectural legibility and narrative with the genius loci to enhance spatial readability and ensure richer description is the best way to accomplish this goal. A space syntax-based visibility graph analysis then determines how to create a legible space with a rich narrative for museum visitors. This is a quantitative method creating a museum's genius loci and provides architects with a standardized design method for creating a building's social culture. Finally, the Memorial Hall of the Victims in Nanjing Massacre by Japanese Invaders explains how spatial visibility creates and affects the genius loci.
\end{abstract}

\section{Introduction}

Contemporary buildings constructed in a standardised way and through mass production tend to have a rigid architectural style and usually lack personality. The phenomenon of lost architectural characteristics, regardless of the user's specific lifestyle and separated from their environment, is called 'instant environment machine'[1]. This design pattern focuses on analysing architectural organisations and functions, but it ignores perceptual experience, which results in the lack of a connection between space and its users. Designers started introducing phenomenological theory to make the current architectural style less rigid. Heidegger's interpretive phenomenology and Merleau-Ponty's perceptual phenomenology is widely applied in architecture. In architectural theory and based on Heidegger's phenomenology, Schulz[2,3,4] proposed the notion of place and genius loci that emphasizes the meaning of architecture as human experience. A group of architects including Pallasmaa[5,6] and Zumthor[7] has applied perceptual phenomenology to architectural theory.

Architectural phenomenology is a concept that allows designers to visualize buildings from the perspective of the human perceptual experience. However, the expression of phenomenology in design is based on emotions that depict space through words such as 'sense' and 'spirit'. These lacks standards of rationalisation to explain how to apply phenomenology in design. As a result, architects need a quantitative analysis method to guide the application of phenomenology in designing space. Spatial syntax is a quantitative analysis method that can guide architectural design. For example, Tate Britain Gallery evaluates different expansion projects with space syntax theory that assesses which configurations can attract more visitors[8]. Spatial syntax is similar to some topics in architectural phenomenology (the unity of the objective world and thinking, place and real-life experiences, and spatial configuration). It is therefore possible to combine spatial syntax with the phenomenology of architecture and place. This is an effective way to find the quantitative applications of phenomenology during the process of design. Seamon[9] argues that there are three reasons that architectural phenomenology can be combined with spatial syntax theory: 1) Hillier and his colleagues demonstrate that the spatial qualities of the built environment play a significant role in street life; 2) Space syntax is a quantitative method for explaining why the relationship between physical and human worlds makes such a difference and why particular city streets and street networks are more or less active; 3 ) Hillier identifies the type of street network that supports a lively public life. In response to Seamon, Hillier[10] 
conducted a rational and sentimental analysis of the space and discussed the possibility of combining the two theories regarding the local and global aspects of the building's configuration and phenomena. In addition, in practical research on combining architectural phenomenology and spatial syntax, Sailer[11] uses spatial syntax to quantitatively describe the relationship between space and social phenomena in the workplace. Zhou[12] uses the axial line of spatial syntax to explore the reasons for the formation of historical and cultural sites, including physical setting and objects.

The existing practical research on the combination of spatial syntax and phenomenology remains in its preliminary stages, as it focuses on theoretical possibilities. However, there is almost no research explore a quantitative analysis on application of architectural phenomenology using spatial syntax, especially regarding the concept of place and genius loci in architectural phenomenology. This study is an analysis of how to shape the genius loci in a museum by using the space syntax to quantitatively analyse the visibility of space. This paper examines the influence of the visibility of space on the readability and narrative of space. This means that museum visitors' sense of direction and identity depends on spatial visibility. It also helps designers create a gallery's genius loci. Finally, taking the Memorial Hall of the Victims in Nanjing Massacre by Japanese Invaders as an example, and quantitatively analyses how its genius loci is created. This research rationally interprets the perceptual theory of architectural phenomenology to provide a quantitative analysis method for how to create genius loci in design. The idea of creating museums' genius loci quantitatively can become a design standard for designer create more comfortable and lively museum for visitors in design process.

\section{Spatial Visibility Affects the Legibility and Narrative of a Museum}

\subsection{The Concept of Spatial Visibility}

According to Camilo[13] "Vision is the essence of the feeling in a space". Based on visual perception in architecture, there has been extensive research on spatial analysis. This has included Camilo's summary of the organisational principles of architecture through a study of the visual perception and impression of architecture in the medieval city. Traditional visual analysis of architecture provides a way to recognize complex spaces from the perspective of architectural art. However, an analysis method based on perception is too subjective and lacks scientific criteria.

The limitations of traditional visual methods force producer to find a scientific method for analysing visual data. The most basic meaning of visibility is determining the extent to which two points in space are uninterrupted by obstacles. Due to an environment's visual data, an individual can move in a space and interact directly with this environment without the intervention of thinking. This is a direct intuition called the "affordance" of the space[14]. Affordance allows one to look at something and intuitively understand how to interact with it. Therefore, spatial visibility can also be directly applied to people, without the influence of external factors. These factors can guide human behavior and activities. Studying the most basic visual reactions to human behavior can help further understand the interactions between individuals and space.

Visibility graph analysis of spatial syntax is a typical method for analysing spatial visibility. Visibility graph analysis has many successful cases and research achievements in the field of interior and exterior space research and urban design. This includes Aazam's[15] study on religious architecture through space syntax, Cil's[16] study on residential space, Tzortzi's[17] study on museum space, and Wineman's[18] study on workplace research. A visibility graph analysis of spatial configuration will reveal its logical relationship with human perception, movement, economic phenomena, social culture and even religious meaning.

\subsection{Spatial Visibility Influences the Legibility of a Museum}

Visibility analysis of space is a useful quantitative method to interpret the impact of spatial visibility on human behaviour and cognition. This is especially true when explaining an exhibit's readability. The exhibit area is relatively closed off, and its visibility is relatively poor. In this kind of environment, the information transmitted is rather simple, so the space's legibility is better. Visitors will be more focused on an exhibit while viewing it and thereby do not need to invest too much effort in 'exploration'. There is also better visibility when choosing a route through a building, as there is an extensive amount of spatial data transmission. Therefore, visitors more readily understand the data transmitted by a space. This makes it easier to decide on a route during the wayfinding process.

In the first layer of meaning, the experience of museum visiting is interpreted as a process of exploration. This process will be influenced by the visibility of a museum's layout. In the case of an open plan science exhibition, Wineman[19] found that an exhibit placed in a more easily seen a closer place will more easily attract visitor. The wide field of vision as the 'affordance' of space unconsciously guides visitors closer to the exhibits with better visibility and reachability. However, this 'visibility' can also distract visitors. In an open exhibition space and with a wider range of options, visitors will need to make more decisions regarding which path to follow[20]. Excessive visual choices and route selection options often transmit a large amount of complicated spatial data. This results in the deterioration of the space's readability, while visitors may also feel disoriented.

In the second layer of meaning, the visibility of space can affect decision-making behaviour during the wayfinding process. The actions of people during the wayfinding process in a virtual urban environment were recorded and compared with a visual analysis of an actual urban environment. This experiment revealed that the places where people often stay for a short time while they are trying to orient themselves are often those with a longer strategic viewing point (the longest diameter) and a larger visible range (viewing area). These short resting points are 
not close to walls and other occluded regions, but mostly road intersections or turning points[21]. Turner[22] also expresses a similar view. During the wayfinding process, the areas with a better visual range are considered the decision points where people will stop and decide how to continue towards their destination. When a building has less decision points with a good visual range, obtaining definite spatial data will be difficult. This is due to the complete or partial obscuration of the intended destination. Therefore, the readability of this space is weak, similar to a maze. The layout of this space will confuse visitors and cause them to lose their sense of direction.

\subsection{Spatial Visibility Influences the Narrative of a Museum}

Museums convey the content of an exhibition to their visitors through narrative expression. This is created in a specific order and is more vivid compared to text and pictures. Visitors can identify with a museum's historical spirit and develop a sense of identity relative to the museum.

Spatial visibility influences the narrative of a museum by influencing the spatial atmosphere and spatial connection. The space within a museum can have an open or closed spatial atmosphere. An open one can provide visitors with a wealth of information to help them understand a particular aspect of the exhibit. A closed one can create a depressing mood. This is conducive to the emotional expression of some memorial museums. In addition to the creation of spatial atmosphere, spatial visibility creates an effective narrative strategy. This is accomplished through the spatial connection and spatial organization that transmits the different meaning of the museum. For example, the spatial structure of the fourth floor of the Museum of Modern Art (MoMA) Extension in New York City has a more rigorous logical relationship with its narrative plots. In addition, with the help of the visual relationship between showrooms and exhibits, the artistic trend behind the exhibits is closely linked to enhance [MoMA's] artistic appeal[23]. The interrelationship between sculptures in the Castelvecchio Art Museum [in Verona, Italy] also conveys the meaning behind the exhibits[24]. Connections between one space and another space are created when visual connections are produced.

\subsection{Spatial Visibility Analysis as a Quantitative Method Creates the Genius Loci of a Museum}

Interpreting the legibility and narrative of space and its relationship with spatial visibility can help one understand how it determines the sense of direction and identity (the two characteristics of the genius loci) of a museum. Therefore, the visibility of space can shape the spirit of a museum. Visual graphic analysis based on spatial syntax is a rational quantitative analysis. It can explore how spatial visibility creates a museum's genius loci. This is a rational way to assist designers in completing the design of a museum.

\section{Case Study}

\subsection{Research Goals}

The focus of this paper is the museum. Visual graphic analysis based on spatial syntax is its method of further understanding the formation of the genius loci of a museum. This method is also applied to explain how spatial visibility affects the readability and narrative of a museum.

\subsection{Research Focus}

Memorial Hall of the Victims in Nanjing Massacre by Japanese Invaders (Memorial Hall) is a memorial museum for residents of Nanjing killed by the Imperial Japanese Army during the Nanjing Massacre (December 13, 1937 January 1938). It is in an area of Nanjing's Jianye District called Jiangdongmen. This area was the site of one of the execution grounds and mass burial places during this event. Memorial Hall has become an important site for many people from across the world to pray for peace. It is also an educational site for historical and cultural exchanges. The Memorial Hall combines three parts ('War', 'Killing' and 'Peace') in sequence from east to west. 'War' is comprised of the 'Sculpture Square', 'Assembly Square' and the 'Exhibition Hall for Historical Relics' with a Nanjing Massacre display. 'Killing' is comprised of the 'Site Square', 'Room for Remains', 'Mass Grave', and the 'Meditation Hall'. Finally, 'Peace' is comprised of 'Peace Park'. In this paper, the area under study is divided into six parts: 'Sculpture Square', 'Assembly Square', 'Mourning Square', 'Site Square', 'Mourning Area' and 'Peace Park' based on the function of each site (see Figure1). Each of these also contains a large amount of public art. In the Memorial Hall, the designer places the "Exhibition Hall for Historical Relics' on the east side and 'Peace Park' on the west side. These two places are linked through the 'Assembly Square', 'Mourning Square', 'Site Square' and the 'Mourning Area'. This layout uses the 'Assembly Square' as the 'overture', the 'Exhibition Hall for Historical Relics' for 'paving', the 'Mourning Area' is the 'climax' in all space and 'Peace Park' as the 'end', completing the layout of the entire sequence. The experiment focuses on the visual relationship between the six parts and their public art (not considering the indoor exhibition area) by applying the visibility graph analysis of the spatial syntax.

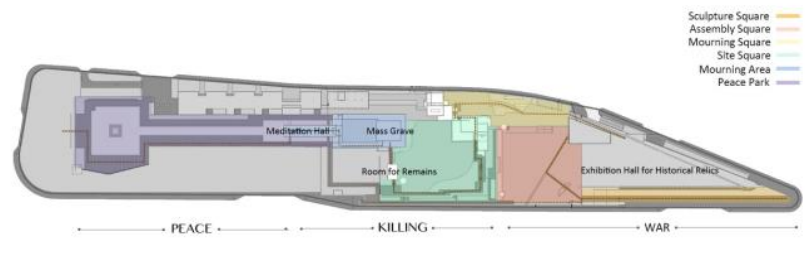

Fig. 1. Regional division diagram.

\subsection{Spatial Visibility Modeling the Sense of Direction}

Randomly observing and recording the effective movements of 84 respondents in the six parts of Memorial Hall and overlaying all of their paths results in a superimposed diagram (Figure 2). It shows that these paths have a larger overlap coefficient with the design of the tour route (the red line in Figure 1). Among them, the paths in 'Sculpture 
Square', 'Mourning Area', and 'Peace Park' show a high degree of concentration and have less 'exploration' trails (an uncertain circuitous pace). There are a few 'exploration' trails in the 'Mourning Area' and 'Site Square'. There are also many 'exploration' trails in the 'Assembly Square'. Following some 'exploration', the trails will change their course and eventually return to the intended route. Figure 3 shows the overlap between the route overlay and connectivity diagram based on space syntax as they appear in Memorial Hall. It can be seen that this place has poor connectivity (the colder part of the figure). Visitors' walking routes also indicate a high coincidence degree in 'Sculpture Square', 'Mourning Area' and 'Mourning Square' ('Peace Park' is not included in this analysis due to the restrictions of its reflecting pool). On the contrary, areas such as the 'Assembly Square' have high connectivity (the warm part of the figure) and more 'exploration' trails. These highconnectivity areas are more likely to exhibit 'exploration' behavior despite the presence of T-shaped passageways guiding visitors through the museum ('Site Square' indicates almost no 'exploration' due to space restrictions). In Figure 3, it is easier to produce 'exploration' behaviors in the warmer selection points (B, C, and D). However, when the decision point has a sufficiently high degree of connection, such as between point $\mathrm{A}$ and point $\mathrm{E}$, the visitor path will change significantly. The results show that the visitors involved in the experiment demonstrate a good sense of direction. While they are in Memorial Hall, they tour the facility based on the intended route. In areas with poor visibility (lower connectivity, as illustrated in Figure 3), such as 'Sculpture Square' and 'Mourning Area', the visitors' walking paths are clearer with less interruptions in their 'exploration' patterns. On the contrary, there is good visibility in the 'Assembly Square'. In this location, visitors' trails appear more 'casual' due to their wide field of vision. This may indicate that visitors may require additional time or walking distance to establish their sense of direction. In terms of the overall study area, points B, C, and D demonstrated poor visibility compared to points A and E. At points $\mathrm{B}, \mathrm{C}$, and $\mathrm{D}$, visitors will encounter interference. This results in 'exploration' patterns that cause them to lose their sense of direction. In contrast, points A and E demonstrated good visibility. At these locations, visitors can quickly make corrections to their routes without losing their sense of direction.

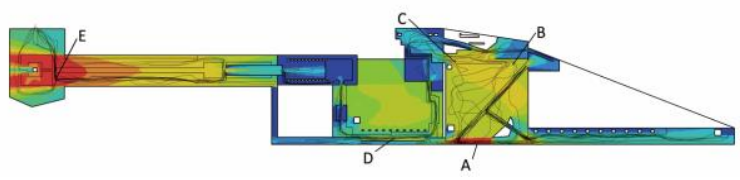

Fig. 2. Route overlay diagram.

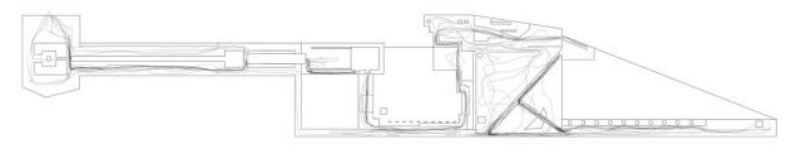

Fig. 3. Route overlay on connectivity diagram.

\subsection{Spatial Visibility Modeling Identity}

After comparing the circulation with the connectivity diagram, it is evident that there is an alternating level of visibility for each area in Memorial Hall (Figure 4). The visibility is relatively low inside the 'Sculpture Square' at the entrance, it is high inside the 'Assembly Square', it decreases inside the 'Mourning Area' after visitors exit the 'Exhibition Hall for Historical Relics', and it increases once more inside the 'Site Square'. There is also an alternating level of visibility in 'Mourning Area' and 'Peace Park'. There are also five public art pieces depicted in Figure 5: 1) 'Cry of Innocent People', 2) 'The Monument', 3) 'The Great Bell of Peace', 4) 'Call from a Mother' and 5) 'Irene Sculpture'. These have several interesting features that enhance their visual relationship.

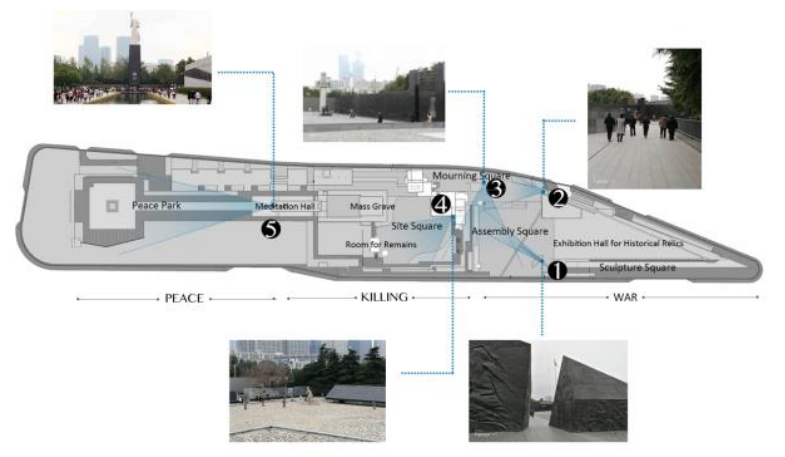

Fig. 4. Location of public art works on connectivity diagram.

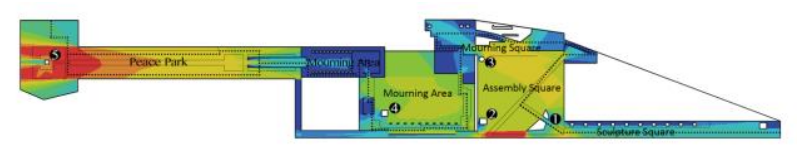

Fig. 5. Picture of public art works.

Sculpture 1 is a large irregular geometric megalith divided into two parts. It is located at the junction of the 'Sculpture Square' and the 'Assembly Square'. Due to the obstruction created by this sculpture, the visibility of the entire 'Sculpture Square' is poor. Visitors can barely see the 'Wall of Calamity' at the 'Assembly Square' through the opening in the middle of Sculpture 1 (No. 1 of Figure 6). Although 'The Great Bell of Peace' is located in the 'Assembly Square', it can be directly seen when visitors leave the 'Exhibition Hall for Historical Relics' (No. 2 of Figure 6). Sculpture 2 ('The Monument') is engraved with the dates '1937.12.13-1938.1' (the Nanjing Massacre's duration). Visitors can clearly see this row of figures in the 'Mourning Area'. The dates are oriented towards the 'Mourning Area' (No. 3 of Figure 6). When visitors step into the 'Site Square' from the 'Mourning Area', the scope of the visual field remains in front of Sculpture 4 ('Call from a Mother') (No. 4 of Figure 6). Finally, at the exit of 'Meditation Hall', the area of vision includes Sculpture 5 ('Irene Sculpture'). Visitors can interact with this sculpture by viewing it as it is depicted in No. 5 of Figure 6. 


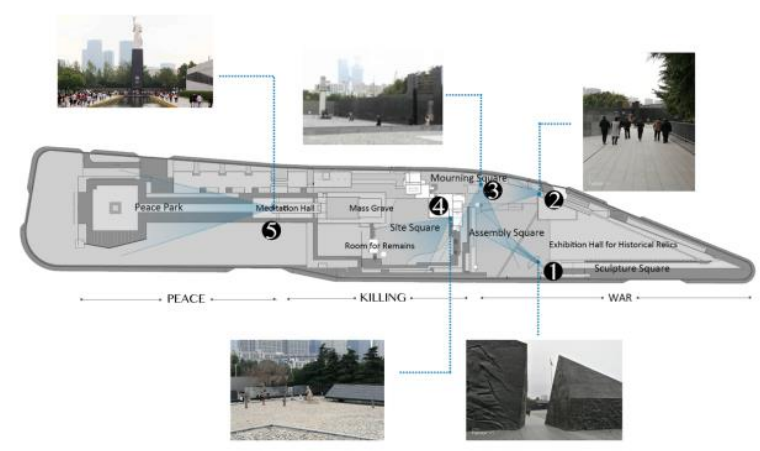

Fig. 6. The relationship between the public art works.

The results show that when visitors enter the Memorial Hall, the visibility of the 'Sculpture Square' is low. This is due to it being blocked by Sculpture 1 ('Cry of Innocent People'). The square is also strip-shaped, giving a closed feeling that allows visitors to focus on two large sculptures depicting scenes of people attempting to escape the violence of the massacre. This effectively creates an intensely emotional experience. At the end of the 'Sculpture Square', visitors can vaguely see the words 'Memorial Hall of the Victims in Nanjing Massacre by Japanese Invaders' carved on the 'Wall of Calamity' from the gap of the 'Cry of Innocent People' when they approach the 'Assembly Square'. These signals the official start of the visit. The field of vision becomes broader through the crevices leading into the 'Assembly Square'. At this point, the content of the exhibition is simply and directly revealed. This is the "prelude" for the overall experience and an introduction to the visit. After this section, visitors can easily enter the 'Exhibition Hall for Historical Relics' due to the wide field of vision of the 'Assembly Square'. When the visitors walk out of the 'Exhibition Hall for Historical Relics', they see the 'The Monument' behind 'The Great Bell of Peace'. This indicates that the cruelty of war has become a distant memory. At the end of the 'War' section, the spatial visibility decreases once again. This closed environment creates the impression of impending doom. As visitors enter the 'climax' part of the Memorial Hall - the 'Killing' section, their vision becomes clear once again. At this point, the human remains and Sculpture 4 comes into view. The moment that visitors enter the 'Killing' section, their eyes face this sculpture. This work of art was created to make people feel a sense of death without life after being killed. As visitors enter the 'Mourning Area' and the tombstone erected in this site, they experience the most obstructed view of the entire exhibition. This creates an emotionally suppressed atmosphere. Finally, after viewing the 'Meditation Hall', the overall sentiment starts to ease. The field of vision widens in 'Peace Park'. This atmosphere is designed to encourage visitors to focus on realizing a more peaceful world. When visitors exit the 'Meditation Hall', Sculpture 5 ('Peace') is situated at the end of the square and directly in the center of visitors' field of vision. The exit of 'Meditation Hall' and Sculpture 5 are positioned on the same axis. This focuses visitors' eyes on Sculpture 5. This work of art represents the importance of peace for humanity. The orderliness and space within the Memorial Hall creates different sense experiences based on the visibility of each of its sections. This is combined with the visual relationship between the five works of public art and the surrounding space. These elements of the Memorial Hall recount the history of the Nanjing Massacre. They are designed to form a sense of identity through establishing an emotional connection with its visitors.

\section{Conclusion}

As a place have historical significance, a museum should have a spiritual connotation, in addition to the educational contents of the museum display. How to provide visitors with a spiritual education that gives visitors a sense of identity and enjoyment is the key point that museum designers need to think about in their design process. So, designers need to adopt a more scientific design method and design flow when introducing the genius loci of architectural phenomenology into museum design. The spirit of the museum's place has two main connotations. These are a sense of direction and identity. In the museum design, these two parts are mainly determined by the readability and narrative of space. The readability and narrative of space can be quantitatively analyzed through spatial visualization based on spatial syntax theory. This provides a data-oriented guide for designers on how to create a genius loci when designing a museum. Compared with previous phenomena that rely solely on emotion, a method applying experience as it relates to architectural design is more scientific. Perceptual architectural phenomenology has practical applications for establishing scientific standards.

\section{Acknowledgments}

This project was supported by the 2018 Jiangsu University Philosophy and Social Science Research Fund Project Grant (No.2018SJA2177)

\section{References}

1. Edward Relph, 'Modernity and the Reclamation of Place', Dwelling, seeing, and designing: Toward a phenomenological ecology, 2 (1993).

2. Christian Norberg-Schulz, Existence, Space \& Architecture (New York: Praeger, 1971).

3. Genius Loci: Towards a Phenomenology of Architecture (Rizzoli, 1980).

4. 'The Concept of Dwelling on the Wayto Figurative Architecture', (1985).

5. Juhani Pallasmaa, 'An Architecture of the Seven Senses', ARCHITECTURE AND URBANISM-TOKYO(1994), 27-38.

6. The Eyes of the Skin: Architecture and the Senses (John Wiley \& Sons, 2012).

7. P Zumthor, M Oberli Turner, and C Schelbert, 'Binet., H., 2006', Thinking architecture.

8. Bill Hillier, and Kali Tzortzi, 'Space Syntax: The Language of Museum Space', A companion to museum studies (2006), 282-301. 
9. David Seamon, 'The Life of the Place: A Phenomenological Commentary on Bill Hillier's Theory of Space Syntax', NA, 7 (2015).

10. Bill Hillier, 'Between Social Physics and Phenomenology', (2005).

11. Kerstin Sailer, and Alan Penn, 'The Performance of Space-Exploring Social and Spatial Phenomena of Interaction Patterns in an Organisation', in Proceedings of the Architecture and Phenomenology Conference (Faculty of Architecture and Town Planning, The Technion, Israel Institute of Technology, 2007).

12. Xuan Zhou, and Zheng Lu, 'The Interpretation of Place Phenomenology Based on Space Syntax Theory', in Advanced Materials Research (Trans Tech Publ, 2013), pp. 422-28.

13. Camillo Sitte, and Charles Thomas Stewart, The Art of Building Cities: City Building According to Its Artistic Fundamentals (Reinhold Publishing Corporation New York, 1945).

14. James J Gibson, The Ecological Approach to Visual Perception: Classic Edition (Psychology Press, 2014).

15. Ziad Aazam, 'The Social Logic of the Mosque: A Study in Building Typology', in 6th International Space Syntax Symposium Proceedings Book, ed (2007), pp. 1-1

16. Ela Cil, 'Space Syntax Analysis of the Twentieth Century Transformation of Kula', Journal of the Faculty of Engineering and Architecture of Gazi University, 23 (2008), 283-93.

17. Kali Tzortzi, 'Museum Building Design and Exhibition Layout', in Proceedings of the 6th International Space Syntax Symposium, Istanbul, Turkey (2007), p. 072.
18. Jean Wineman, and Anirban Adhya, 'Enhancing Workspace Performance: Predicting the Influence of Spatial and Psychosocial Factors on Job Satisfaction', in Proceedings, 6th International Space Syntax Symposium, İstanbul (2007), pp. 1-15.

19. Jean D Wineman, and John Peponis, 'Constructing Spatial Meaning: Spatial Affordances in Museum Design', Environment and Behavior, 42 (2010), 86-109.

20. Ipek Kaynar, 'Visibility, Movement Paths and Preferences in Open Plan Museums: An Observational and Descriptive Study of the Ann Arbor Hands-on Museum', in Proceedings of the 5th International Space Syntax Symposium, Delft, The Netherlands (2005).

21. Ruth Alison Conroy, 'Spatial Navigation in Immersive Virtual Environments' (Citeseer, 2001).

22. Alasdair Turner, Maria Doxa, David O'sullivan, and Alan Penn, 'From Isovists to Visibility Graphs: A Methodology for the Analysis of Architectural Space', Environment and Planning B: Planning and design, 28 (2001), 103-21.

23. Sophia Psarra, Jean Wineman, Ying $\mathrm{Xu}$, and Ipek Kaynar, 'Tracing the Modern: Space, Narrative and Exploration in the Museum of Modern Art, New York', in International Space Syntax Symposium, Istanbul, Turkey (2007).

24. Gianna Stavroulaki, and John Peponis, 'The Spatial Construction of Seeing at Castelvecchio', in Proceedings of the 4th 8.5 磅 International Space Syntax Symposium (University College London London, 2003), pp. 66.61-66.14. 